\title{
Patient satisfaction with mobile clinic services in a remote rural area of Saudi Arabia
}

B. Aljasir ${ }^{1,2}$ and M.S. Alghamdi ${ }^{3}$

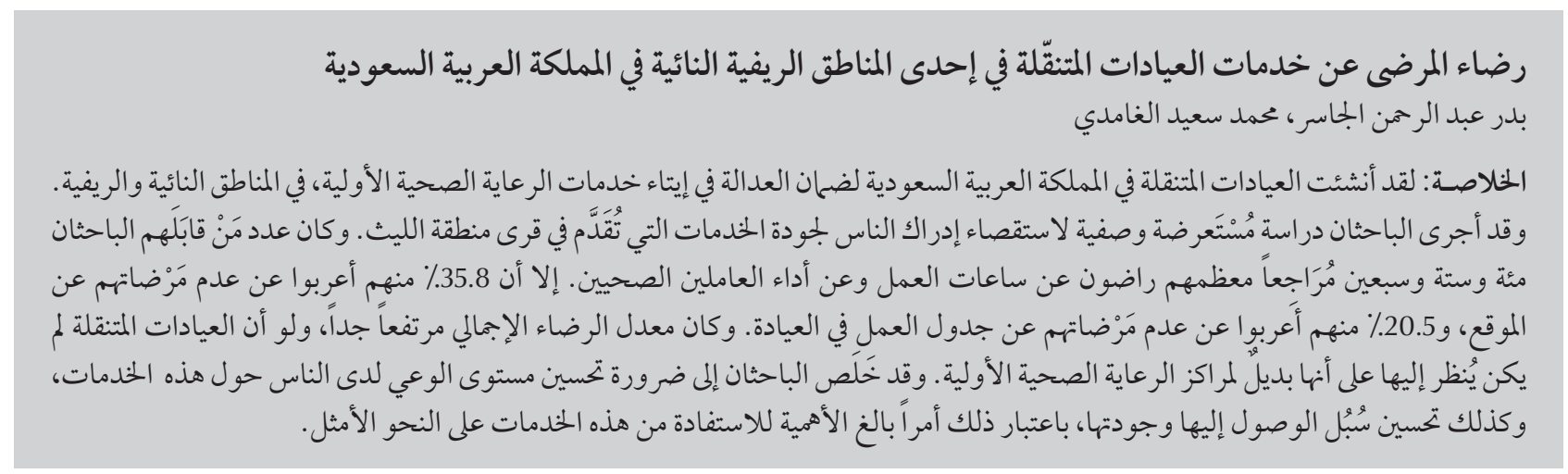

ABSTRACT Mobile clinics have been established in Saudi Arabia to facilitate the equitable delivery of primary health care services in remote and rural areas. A descriptive cross-sectional study was conducted to investigate the perceived quality of services provided to villages in the Al-Laith region. The majority of the 176 clients interviewed were satisfied with the working hours and health staff. However, $35.8 \%$ viewed the location as unsatisfactory and $20.5 \%$ were dissatisfied with the clinic schedule. Overall satisfaction was very high, although the mobile clinics were not viewed as substitutes for primary health care centres. Public awareness of the service needs to be improved and better access and quality of services are important for optimal service provision.

\section{Niveau de satisfaction des patients vis-à-vis des services sanitaires mobiles dans une zone rurale isolée en Arabie saoudite}

RÉSUMÉ Des dispensaires mobiles ont été créés en Arabie saoudite pour faciliter une prestation équitable de services de soins de santé primaires dans les zones isolées et rurales. Une étude transversale et descriptive a été réalisée afin d'étudier la perception de la qualité des services fournis aux villages de la région d'Al-Laith. La majorité des 176 personnes interrogées étaient satisfaites des horaires et du personnel de santé. Mais 35,8\% d'entre elles considéraient que l'emplacement était insatisfaisant, de même que le suivi médical (20,5\% des personnes interrogées). Le taux de satisfaction global était très élevé, bien que les services mobiles ne soient pas perçus comme des substituts des centres de soins de santé primaires. Il est nécessaire de mieux faire connaitre cette structure au public ; I'amélioration de l'accès aux services et de la qualité de ceux-ci est importante en vue d'une prestation optimale. 


\section{Introduction}

Saudi Arabia is a geographically varied country whose population reflects a range of social and cultural backgrounds. Primary health care services were instituted in Saudi Arabia in 1983 [1] and comprise a large network of primary care centres covering most of the country [2]. Health authorities deploy continuing efforts to make these services comprehensive and capable of providing high-quality preventive and curative services to citizens and residents [3-5]. There are concerns, however, about the availability of appropriate facilities to people living in remote and rural areas. While road and air transportation provides accessibility for rural patients to high-quality emergency care in hospitals, in many rural areas the travel time to a facility providing routine or ongoing health care services can be considerable because of difficult road conditions and a lack of adequate transport. This poses particular problems for elderly people and others such as pregnant women and children, who require medical care on a regular basis.

To improve equity in the distribution of health care services and to reach those in high need the Ministry of Health, via the Primary Health Directorate, has established a mobile clinic service. As demonstrated elsewhere, the potential clients of mobile health clinics are people living in medically underserved areas, who are likely to be poor and elderly and would otherwise not seek medical care [6].

Needs assessment is always an important starting point for determining the specific needs of a population and thus for effective planning of health care services $[7,8]$. To be successful, our mobile clinic service requires evaluation and monitoring with respect to aspects such as location, types of services offered, staffing and the specific needs of the target population. The aim of the present study was to assess consumer satisfaction with the mobile clinics in
Al-Laith region of Saudi Arabia. To the best of our knowledge, this research is the first to be conducted on mobile clinics in the Middle East and among the very few studies internationally that have provided a comprehensive evaluation of such services in rural areas.

\section{Methods}

\section{Study setting}

The study was conducted in Al-Laith governorate, a remote rural area comprising 12 administrative emirates in the south-western region of Saudi Arabia. It is divided into 2 main areas: a coastal region and a mountainous region. The total population was about 120000 in the 1995 census. The health services in the area are provided by 25 primary health care centres and 2 small hospitals.

\section{Mobile health clinics in Al- Laith}

Two 4-wheel-drive mobile clinics were designed to provide, as much as possible, the work capabilities of a standard clinic. They were intended to transport and provide working space for a doctor and a nurse (in addition to the driver) and to contain a well-equipped clinic and a laboratory capable of providing commonly needed tests. The airconditioned mobile clinic accommodated a bed, drawers for the storage of instruments and bandages, and a refrigerator for medication and vaccine storage. The clinic space was connected to the driver's compartment by intercom. The van was fitted with a waste disposal tank designed for hazardous materials. Other safety considerations and the ability to withstand various climate conditions were also taken into account in the design of the vehicle.

Among 42 underserved villages in Al-Laith area, 13 were selected for the mobile health clinics service on the basis of their remote location and complete lack of health care services.
The villages were situated between 20 and $100 \mathrm{~km}$ from the nearest primary health care centre and each was visited 1 day per week on a regular schedule. The 2 mobile clinics were scheduled to depart from the main 2 centres located in Al-Laith area at 06:00 each day in order to provide health care services for the assigned village from 08:00-09:00 until 15:00.

\section{Research design and sample}

A descriptive cross-sectional research design was used to evaluate consumer satisfaction with the mobile heath clinic services. Ethical approval was obtained from the local health authorities in AlLaith.

The sample for the study was users of the mobile clinics. The 2 mobile clinics serve a population that has been estimated at approximately 17000 on the basis of the national census conducted in 1995. A convenience sample of 200 clients - 100 for each mobile clinicwas planned. To be eligible for inclusion in the study, clients were required to be 16 years or over, able to communicate and fully willing to participate. A total of 690 clients visited the mobile clinics during the research period (April 2006). The target was to select 5 or 6 clients by a simple random process at each visit. However, because of time constraints and technical problems with the mobile clinic in the mountainous region, only 197 clients were invited to participate and of these, 176 were included in the study sample from 30 visits, a response rate of $89.3 \%$.

\section{Data collection tool}

A structured interview questionnaire was designed to elicit the opinions of mobile clinic consumers about the services provided and their expectations and needs. Close-ended questions were used with questions about sociodemographic characteristics, general medical history and health-related behaviours, perceptions about the quality of services provided in relation to the structure of 
the mobile clinics (human resources, equipment, facilities, supplies), the process of care (system, communication, quality control, policies and procedures), and the outcome of care, including patient satisfaction, as well as suggestions for improvement. The interviews were conducted by welltrained interviewers and took place in the mobile clinics during the scheduled break times.

The data collection tool was prepared and then tested on a sample who were not subsequently included in the main study sample $(n=20)$. The aim of the pilot study was to test the clarity and practicality of the tools as well as their internal consistency. Among the tested questions, 21 items were constructed to have an ordinal scale to determine consumers' satisfaction with the various aspects of the health care services. Each item was evaluated separately for its internal consistency by computing the reliability coefficient (Cronbach alpha coefficient). When any of the items showed a negative correlation, recoding of the responses was considered so that all of the items were correlated positively to compute an overall reliability coefficient. Thus, the overall Cronbach alpha coefficient was 0.84 , which is considered high.

Pilot testing also helped to estimate the time needed to conduct the interviews and to completethequestionnaire. Minor modifications to the different data collection tools were needed.

\section{Data management}

For satisfaction with services, the responses "yes," "sometimes" and "no" were scored 2, 1 and 0 , respectively. The total scores for items within a question area were divided by the number of items, giving a mean score for the topic. These scores were converted into a percentage score, and means and standard deviations (SD) were computed. The topic was considered satisfactory if the mean score was $60 \%$ or more and unsatisfactory if the mean score was less than
$60 \%$. The cut-off point of $60 \%$ was used to facilitate comparison with previous research evaluating health care services in the area [9].

\section{Data analysis}

Data entry was done using SPSS, version 11.0. Data cleaning was done and a quality check was conducted for coding and data entry. Data analysis was done using the same program, in addition to the Epi-Info, version 6.04 software package. Data were presented using descriptive statistics in the form of frequencies and percentages for qualitative variables, and ranges, means and SD for quantitative variables. Qualitative variables were compared using the chi-squared test or Fisher exact test, as appropriate. $P$-value $<0.05$ was considered statistically significant.

\section{Results}

Of the 13 villages included in the study, $63.1 \%$ were in coastal areas and $36.9 \%$ in mountainous areas.

The characteristics of the 176 respondents are presented in Table 1. Participants ranged in age from 16 to 76 years, with a mean age of 37.1 years. Most (90.3\%) were men. About onethird (33.3\%) were illiterate, while only $2.8 \%$ were university graduates. More than half (54.0\%) were married. They were mostly unemployed (72.7\%).

Almost all the respondents (93.2\%) had used the mobile clinic service in the past. The most common sources of information about the clinics were sheikhs (tribal leaders) (39.2\%) and friends (35.8\%). The distance from home to the clinic ranged from $0.5 \mathrm{~km}$ to 13.0 $\mathrm{km}$. Before the mobile clinic became operational, the majority (93.2\%) had received services at a primary health care centre in another village, with an average travel time of $56.8 \mathrm{~min}$. However, $51.1 \%$ of respondents were still using this other service, mostly for the treatment of acute diseases in adults (48.6\%).

\begin{tabular}{|c|c|c|}
\hline \multicolumn{3}{|c|}{$\begin{array}{l}\text { Table 1 Characteristics of respondents } \\
\text { of mobile clinic service survey }(n=176)\end{array}$} \\
\hline Variable & \multicolumn{2}{|c|}{ Value } \\
\hline \multicolumn{3}{|l|}{ Age (years) } \\
\hline Range & \multicolumn{2}{|c|}{$16-76$} \\
\hline \multirow[t]{2}{*}{ Mean (SD) } & \multicolumn{2}{|c|}{$37.1(17.6)$} \\
\hline & No. & $\%$ \\
\hline \multicolumn{3}{|l|}{ Sex } \\
\hline Male & 159 & 90.3 \\
\hline Female & 17 & 9.7 \\
\hline \multicolumn{3}{|l|}{ Education } \\
\hline Illiterate & 58 & 33.0 \\
\hline Read/write & 41 & 23.3 \\
\hline Basic & 27 & 15.3 \\
\hline Secondary & 45 & 25.6 \\
\hline University & 2 & 2.8 \\
\hline \multicolumn{3}{|l|}{ Marital status } \\
\hline Single & 68 & 38.6 \\
\hline Married & 95 & 54.0 \\
\hline Widow/widower & 13 & 7.4 \\
\hline \multicolumn{3}{|l|}{ Employment status } \\
\hline Office employee & 6 & 3.4 \\
\hline Skilled worker & 4 & 2.3 \\
\hline Military & 26 & 14.8 \\
\hline Student & 12 & 6.8 \\
\hline Unemployed & 128 & 72.7 \\
\hline
\end{tabular}

$S D=$ standard deviation.

Survey responses with respect to the structure of the mobile clinics are shown in Table 2. The majority of clients were satisfied with the working hours, doctors and nurses, rating them acceptable or good. Meanwhile, more than onethird (35.8\%) viewed the location of the clinic as unsatisfactory and $20.5 \%$ were dissatisfied with the schedule.

The respondents' rating of services provided by mobile clinic is provided in Table 3. Respondents noted the lack of many important services, or services that were not used by them, such as services for people with disabilities, laboratory tests, electrocardiography and vaccinations. Conversely, medications were present in all clinics, and this aspect of care was judged as good by all respondents. Health education services were also provided in most cases and were mostly judged as good (83.5\%). 


\begin{tabular}{|c|c|c|c|c|c|c|}
\hline \multirow[t]{3}{*}{ Criterion } & \multicolumn{6}{|c|}{ Rating } \\
\hline & \multicolumn{2}{|c|}{ Unsatisfactory } & \multicolumn{2}{|c|}{ Acceptable } & \multicolumn{2}{|c|}{ Good } \\
\hline & No. & $\%$ & No. & $\%$ & No. & $\%$ \\
\hline Location & 63 & 35.8 & 11 & 6.3 & 102 & 58.0 \\
\hline Schedule (1/week) & 36 & 20.5 & 48 & 27.3 & 92 & 52.3 \\
\hline Working hours & 9 & 5.1 & 23 & 13.1 & 144 & 81.8 \\
\hline Doctors & 0 & 0.0 & 2 & 1.1 & 174 & 98.9 \\
\hline Nurses & 0 & 0.0 & 2 & 1.1 & 174 & 98.9 \\
\hline
\end{tabular}

The overall satisfaction of the mobile clinic users was very high; the structure of the services and the types of services provided were rated as satisfactory by $94.9 \%$ and $98.9 \%$, respectively. There was a statistically significant difference between respondents from mountainous areas and those from coastal areas in their level of satisfaction with the mobile clinic structure, with more coastal residents expressing satisfaction (100.0\%) than those from the mountainous region $(91.9 \%)(P=0.03)$.

The overall opinion of mobile clinic users about the services compared with primary health care centres in other villages is shown in Table 4. Most users considered the services less satisfactory or equal to those provided in primary health care centres. About two-thirds (62.5\%) viewed the mobile services as of lower quality in comparison with services provided by primary health care centres. The majority rated the services provided as good in part or in total, but $90.9 \%$ of the users did not feel that they could depend on the mobile clinics to meet all of their routine or emergency care needs.

\section{Discussion}

Ideally mobile clinics provide services that extend from childhood and adult immunizations, to taking medical histories and performing physical examinations, providing well-child care and chronic illness management, health education and counselling, geriatric home visits and health maintenance. However, the accessibility and utilization of mobile health services vary greatly according to location and other characteristics, including how well the services are publicized [10].

The mobile clinics involved in the present study provide health care to underserved and difficult-to-reach areas whose underprivileged status might be inferred from the personal characteristics of the respondents, of whom about one-third were illiterate and more than two-thirds were unemployed. These rates are higher than the national illiteracy rate (17.1\%, reported in 2005) [11] and the national unemployment rate $(11.2 \%$ and $9.8 \%$, reported in 2006 and 2008, respectively) [12].

The low prevalence of women in our study was expected in this rural area in view of cultural barriers that discourage participation in such surveys as well as visits to health facilities by women,

\begin{tabular}{|c|c|c|c|c|c|c|c|c|}
\hline \multirow[t]{2}{*}{ Health service } & \multicolumn{2}{|c|}{$\begin{array}{l}\text { Not applicable } \\
\text { (unavailable to clients) }\end{array}$} & \multicolumn{2}{|c|}{ Unsatisfactory } & \multicolumn{2}{|c|}{ Acceptable } & \multicolumn{2}{|c|}{ Good } \\
\hline & No. & $\%$ & No. & $\%$ & No. & $\%$ & No. & $\%$ \\
\hline Chronic diseases & 9 & 5.1 & 0 & 0.0 & 81 & 46.0 & 86 & 48.9 \\
\hline $\begin{array}{l}\text { Maternity and well-baby } \\
\text { health services }\end{array}$ & 88 & 50.0 & 13 & 7.4 & 50 & 28.4 & 25 & 14.2 \\
\hline Accidents & 45 & 25.6 & 18 & 10.2 & 65 & 36.9 & 48 & 27.3 \\
\hline Vaccinations & 153 & 85.9 & 2 & 1.1 & 16 & 9.1 & 5 & 2.8 \\
\hline Health education & 27 & 15.3 & 0 & 0.0 & 2 & 1.1 & 147 & 83.5 \\
\hline Infectious diseases & 66 & 37.5 & 0 & 0.0 & 10 & 5.7 & 100 & 56.8 \\
\hline Mental health & 109 & 61.9 & 8 & 4.5 & 0 & 0.0 & 59 & 33.5 \\
\hline Special needs (disabilities) & 167 & 94.9 & 8 & 4.5 & 0 & 0.0 & 1 & 0.6 \\
\hline Emergency & 41 & 23.3 & 0 & 0.0 & 86 & 48.9 & 49 & 27.8 \\
\hline Laboratory tests & 164 & 93.2 & 0 & 0.0 & 11 & 6.3 & 1 & 0.6 \\
\hline Electrocardiography & 164 & 93.2 & 0 & 0.0 & 11 & 6.3 & 1 & 0.6 \\
\hline Medications & 0 & 0.0 & 0 & 0.0 & 0 & 0.0 & 176 & 100.0 \\
\hline
\end{tabular}




\begin{tabular}{|c|c|c|}
\hline \multicolumn{3}{|c|}{$\begin{array}{l}\text { Table } 4 \text { Respondents' overall opinions about mobile clinic service as comparec } \\
\text { with primary health care centres }(n=176)\end{array}$} \\
\hline Variable & No. & $\%$ \\
\hline \multicolumn{3}{|l|}{$\begin{array}{l}\text { Mobile clinic compared with primary } \\
\text { centre }\end{array}$} \\
\hline Cannot be compared & 50 & 28.4 \\
\hline Provides some services & 103 & 58.5 \\
\hline Provides same services & 21 & 11.9 \\
\hline Provides more services & 2 & 1.1 \\
\hline \multicolumn{3}{|l|}{$\begin{array}{l}\text { Mobile clinic quality of services } \\
\text { compared with primary centre }\end{array}$} \\
\hline Cannot be compared & 42 & 23.9 \\
\hline Provides lower quality services & 110 & 62.5 \\
\hline Provides same quality services & 24 & 13.6 \\
\hline \multicolumn{3}{|l|}{ General opinion about mobile clinics } \\
\hline Waste of money & 18 & 10.2 \\
\hline Good in certain services & 136 & 77.3 \\
\hline Good in all basic services & 21 & 11.9 \\
\hline Good substitute for primary centre & 1 & 0.6 \\
\hline \multicolumn{3}{|l|}{$\begin{array}{l}\text { Mobile clinic is dependable in providing } \\
\text { health care in the area }\end{array}$} \\
\hline No & 160 & 90.9 \\
\hline Yes & 3 & 1.7 \\
\hline Yes, with exceptions & 13 & 7.4 \\
\hline
\end{tabular}

except in urgent situations, and that require women to be accompanied by a male relative. Further, the fact that the clinics were run only by male workers might have discouraged their use by women, who may have travelled to a primary health care centre to receive services from female health care workers. Solutions to overcome this barrier and thus increase the utilization of mobile clinics by women could include recruiting female health care workers or extending the operating hours of mobile clinics until the later hours of the day, which would allow for the return of male relatives from work so that they could accompany female family members and children to the mobile clinic.

The finding that most respondents had learned about the mobile clinics from sheikhs or friends indicates a lack of advertising about the services provided through these clinics to the local community. Therefore, there is a need for more publicity on the part of health authorities with respect to mobile clinics.
Before the mobile clinics became operational, most respondents had obtained services at a primary health care centre in another village, with an average travel time of an hour compared to a few minutes to reach the mobile clinic. About half of the mobile clinic users were still travelling to primary care centres to obtain services not provided by the mobile clinic. However, even though mobile medical programmes do not provide full services, they have the potential to improve equity in health care and disease control by providing services to high-risk individuals who may lack access to care elsewhere [1315]. Mobile clinics in rural areas can play a supporting role in the provision of health care services, and health care authorities can use such technology to improve access and reduce the burden of travel on patients.

Mobile clinics should give emphasis to preventive as well as curative services. In this respect, Swaddiwudhipong has reported that the use of a mobile unit may be an effective means of delivering screening programmes in rural areas where existing screening activities cannot effectively reach the population at risk [16]. Respondents noted that many important services were lacking, or that some services were not relevant to them, such as services for people with disabilities, laboratory tests, electrocardiography and vaccinations (despite the fact that the mobile clinics had been designed to provide such services). Although services related to disabilities might not be applicable to most visitors, the lack of services related to laboratory tests, electrocardiography and vaccination do appear to constitute a weakness of these mobile clinics; the fact that these services were not consistently available indicates a need for improvement. Although health care services related to maternal and infant health were seen by $40.6 \%$ of the participants as acceptable or good, we should keep in mind the under-representation of women in the current sample, which indicates that the services utilized were likely to be related to well-baby care. Conversely, medications were available in all clinics, and this aspect of care was judged as good by all respondents. Health education services were also provided in most cases, and were mostly judged as good. In this regard, current mobile clinic services should be more consistent in the services provided and should include more preventive and screening services as well.

When asked their opinion about the structure of mobile clinics, most respondents expressed satisfaction with the clinic hours, doctors and nurses. However, the dissatisfaction of respondents with the range of services offered indicates a need for more improvement in the services provided and for an ongoing process of determining consumer satisfaction with the services and for gathering suggestions for improvement.

There was a statistically significantly higher level of satisfaction with mobile 
clinic services among coastal residents compared with those frommountainous areas. This may be because the residents of mountainous areas, who have no alternative services nearby, had higher expectations of the mobile clinic. Any lack of service in the mobile clinic would mean a long trip to the nearest primary health care centre for these users. In this regard, providers of health services in rural areas should give special attention to subgroups that may have different needs and require more support. In addition, a quick maintenance process for the mobile clinic is required to maintain service without interruption; technical problems with the mobile clinic in the mountainous areas had an impact on the service. An alternative could be the presence of an extra mobile clinic that could replace that under maintenance, especially for areas with a challenging geographical terrain.

Despite the fact that the overall satisfaction with the mobile clinic was high, most users considered the services less satisfactory than or equal to those provided in primary centres. Moreover, the majority responded that mobile clinics were not dependable in providing services in their area. Health planners and decision-makers should take these opinions into consideration. In addition, there is a need for more information for consumers about the aim of these mobile clinics and the services that should be expected from such alternative health care provision settings.

\section{Conclusion}

The majority of mobile clinic clients were satisfied with the services provided, although a need to provide some important services more consistently and with optimum quality was noted. Issues convening access (location and operating hours) should be reviewed regularly to ensure that they match the needs of the area served. It is recommended that mobile clinics be given more publicity by the health authorities, with clarification about the types of services that they provide. There is a need to improve the utilization of mobile clinic services by women. A rapid maintenance process and a continuous process of assessing the quality of services provided are needed to optimize service provision. Health planners and decision-makers should take into account the ability of mobile clinics to provide good health care in certain settings, while remembering that they cannot be relied upon as substitutes for full-service health centres.

\section{Acknowledgements}

The authors thank the teams who ran the mobile clinics and the local health authorities in Al-Laith area for their participation and support.

\section{References}

1. Khoja TA, Farid SM. Saudi Arabia family health survey 1996: principal report. Riyadh, Saudi Arabia, Ministry of Health, 2003.

2. World health report 2002. Health indicators. Geneva, World Health Organization, 2002.

3. Al Doghaither AH, Saeed AAW, Mohammed BAR. Satisfaction and correlates of patient satisfaction with primary health care center services in Riyadh, Saudi Arabia. Qatar Medical Journal, 2001, 10(2):34-38

4. Al-Ahmadi H, Roland M. Quality of primary health care in Saudi Arabia: a comprehensive review. International Journal for Quality in Health Care, 2005, 17(4):331-346.

5. Al-Sakkak MA et al. Patient satisfaction with primary health care services in Riyadh. Saudi Medical Journal, 2008, 29(3):432436.

6. Fant EW, Thompson KS. Integration of a mobile health care system to deliver mobile health services in Arkansas. Paper presented at 52nd Annual Meeting of the National Rural Electric Cooperative Association, 1994 (http://ww2.mackblackwell. org/web/research/ALL_RESEARCH_PROJECTS/1000s/1015fant/MBTC1015.pdf, accessed 4 May 2010).

7. Bosworth T. Community health needs assessment: the healthcare professionals guide to evaluating the needs in your defined market. New York, McGraw-Hill, 1999.

8. Soriano FI. Conducting needs assessments: a multidisciplinaryapproach. Thousand Oaks, California, Sage Publications, 1995.

9. Aljasir B, Alghamdi M. Health needs among consumers and providers of primary health care services in a rural community in
Saudi Arabia [thesis]. Jedda, Saudi Arabia, Arab Board of Community Medicine, Joint Program of Family and Community Medicine, 2005.

10. Field KS, Briggs DJ. Socio-economic and locational determinants of accessibility and utilization of primary healthcare. Health and Social Care in the Community, 2001, 9(5): 294-308.

11. Reduction in Saudi unemployment rate and increase in job variety. Ministry news 2008. Riyadh, Saudi Arabia, Ministry of Labour and Social Services, 2008.

12. Economic performance. In: Human development report 2007/2008. Fighting climate change: human solidarity in a divided world. New York, United Nations Development Programme, 2008:278.

13. Liebman J, Lamberti MP, Altice F. Effectiveness of a mobile medical van in providing screening services for STDs and HIV. Public Health Nursing, 2002, 19(5):345-353.

14. Edgerley LP et al. Use of a community mobile health van to increase early access to prenatal care. Maternal and Child Health Journal, 2007, 11(3):235-239.

15. McDaniel J, Strauss SS. Development of a nurse practice arrangement in rural Appalachia: triumphs and challenges. Nursing Education Perspectives, 2006, 27(6):302-307.

16. Swaddiwudhipong $\mathrm{W}$ et al. A mobile unit: an effective service for cervical cancer screening among rural Thai women. International Journal of Epidemiology, 1999, 28:35-39. 